\title{
Garantía de la libertad $y$ de la democracia
}

\section{Octavio Arredondo}

John Rawls, Sobre las libertades. Barcelona, Paidós, 1990, 122 pp.

ohn Rawls en su obra Sobre las libertades nos presenta un doble objetivo, primeramente puntualizar algunos aspectos de Teoría de la justicia y segundo analizar nuevamente la función de la justicia en la organización social y la función política para la conformación de un Estado. En esta concepción de justicia que nos propone hay que destacar la justicia como equidad, punto del cual parte, presuponiendo una sociedad bien organizada con igualdad entre todos los individuos, pero para poder partir de este supuesto, Rawls habrá de concebir un Estado originario, haciendo abstracción de la sociedad en la que en realidad nos incrustamos, ya que lo que se propone es plantear las condiciones ideales en que una sociedad pueda desarrollarse con justicia y equidad, no propone un Estado histórico, ni un Estado posible, sino un Estado en que las condiciones sean las necesarias para poder llegar a plantear una serie de puntos que puedan ser aplicados posteriormente en un Estado real.

A partir de este supuesto, de una sociedad de posibilidad o Estado originario, Rawls formula dos puntos o principios fundamentales, dos principios de justicia que los expresa de la siguiente manera:

1. Toda persona tiene igual derecho a un régimen plenamente suficiente de libertades básicas iguales, que sean compatibles con un régimen similar de libertades para todos.

2. Las desigualdades sociales y económicas han de satisfacer dos condiciones. Primero, deben estar asociadas a cargos y posiciones abiertos a todos en las condiciones de una equitativa igualdad de oportunidades; y, segundo, deben procurar el máximo beneficio de los miembros menos aventajados de la sociedad.

De este segundo principio que se divide en dos, el de la igualdad de oportunidades y el de la diferencia, Rawls realmente está postulando tres 
principios que tienen la misma importancia pero que a su vez unos se subordinan a los otros en el orden que han sido expuestos. Estos principios nos llevan a suscribir la noción de un bien común, en la situación de la cual se parte, como situación original en la que se dan las condiciones para que los individuos de la sociedad lleguen a satisfacer las concepciones del bien. En los principios básicos en que fundamenta la concepción del Estado tenemos primeramente el de las libertades básicas que, por su naturaleza, deben ser garantía de que los otros dos puntos puedan llevarse a cabo, ya que sin libertad la igualdad no sería posible y sin ésta el principio de la diferencia tampoco se podría llevar a cabo. Asi en el primer punto, el de las libertades, podemos enumerar dos primordiales que son garantía de que todo individuo pueda acceder a la igualdad: 1 . Libertad de pensamiento y 2 . Libertad de conciencia; a las cuales se les suman otras que son derivadas de las anteriores: libertad fisica, libertad política y libertad de asociación.

Al formular que cada persona debe gozar de libertad para conformar su noción de vida buena, Rawls introduce otra característica que es base para que cada individuo pueda gozar de igualdad en sociedad, ésta es las de los bienes primarios que deben satisfacer las necesidades primordiales que tenemos como miembros de una sociedad que se plantea como necesario que cada uno debe tener igualdad en un Estado democrático.

El darse estos bienes primarios es base y condición para que cada uno pueda reclamar y procurarse otros bienes o preferencias menos básicos. Estos bienes primarios se determinan por las cosas que son necesarias como condiciones sociales y proseguir las concepciones determinadas del bien y desarrollar y ejercer las potestades morales, estos bienes son:

1. Las libertades básicas.

2. La libertad de movimiento y libre elección de ocupación frente a un trasfondo de diversas oportunidades.

3. Potestades y prerrogativas de cargos y puestos de responsabilidad.

4. Ingresos y riqueza, concebidos en términos amplios como medios generales.

5. Las bases sociales del respeto a uno mismo.

Esta formulación de los bienes primarios es otra formulación de lo que son los principios de justicia, primero las libertades básicas seguido de la igualdad de oportunidades como igualdad de acceso al poder y a la toma de decisiones y por último la igualdad económica básica que es el fundamento del autorrespeto.

Para Rawls, estos bienes primarios son aceptados con base en una determinada concepción de la personalidad moral, que subyace a la noción de 
justicia como equidad, puesto que los ciudadanos de una sociedad deben concebirse a si mismos como conciudadanos libres e iguales, y al concebirse de esta manera surge al mismo tiempo la justicia, ya que si hay igualdad es porque existe la libertad, situación que constituye un Estado justo en el que todos han de colaborar de igual manera, estableciendo así una cooperación social. Esta capacidad de cooperar es fundamental, ya que es la concepción de la personalidad moral de cada individuo, con lo que cada uno adquiere dos potestades que determinan su igualdad y libertad. Dichas potestades son:

1. El ser razonable, que es una noción de cooperación equitativa que razonablemente acepta cada participante de la sociedad.

2. El ser racional, que responde a la ventaja de cada individuo: la de concebir y perseguir los bienes particulares.

Estas dos capacidades constituyen una condición necesaria para ser considerado como miembro igual de la sociedad en cuestiones de justicia política. El ser racional es un punto que no es dificil de explicar o comprender, ya que la racionalidad es lo que nos muestra como egoístas que buscamos un provecho propio y es en donde tratamos de satisfacerlo como seres autónomos sin importar los otros individuos sociales, pero al mismo tiempo tenemos la razonabilidad que es lo que decide los términos equitativos de coope. ración y elección social, lo que nos da el punto de una sociedad ordenada y estructurada conforme a un principio básico de cooperación social y equidad en la justicia. Con lo que tenemos dos potestades morales que son la capacidad del sentido de lo recto y de la justicia y la capacidad de una concepción del bien. Estas potestades morales son condiciones necesarias para poder ser miembro de una sociedad, ya que si no existe justicia no podría haber libertades básicas que son fundamento de la igualdad y, por tanto, de reconocimiento mutuo entre los individuos sociales y, por su parte, la concepción del bien es punto fundamental ya que de él existe el respeto al otro, puesto que el respetar y reconocer al otro como igual miembro social nos lleva a vivir en comunidad y a lograr un bienestar que cada uno de nosotros deseamos para nosotros mismos como fundamento de que podemos gozar de cada una de las libertades, desde la de pensamiento y de conciencia hasta la libertad política que es uno de los puntos más álgidos en toda composición social.

A través de una deducción Rawls llega a una idea universal de justicia, válida para todos los tiempos y lugares, independiente de las contingencias históricas, políticas, económicas o culturales, tan buena para las sociedades desarrolladas como para las que no lo son, tan aplicable por gobiernos socialistas, como liberales. La concepción de justicia que Rawls propone, con 
las libertades básicas como principio prioritario, se fundamenta y explica por una razón fundamental: racional y razonable: egoísta y cooperadora. En efecto, las libertades garantizan la igualdad de la cooperación social ya que la sociedad bien ordenada es un bien más amplio que el bien determinado por los intereses privados de los individuos. Además, las libertades son la base del autorrespeto o sentido de la propia valía que consiste en acceder a los bienes o planes de vida particulares, acceder a estrategias de bienestar, ya que el fin de una sociedad justa es alcanzar ese hipotético bien común, y permitir que sus miembros busquen la felicidad o sus bienes privados, al parecer, también suficiente, para lograr ambos bienes. Puesto que mantiene la voluntad de cooperación y la autonomía de cada uno para construir su propia vida de acuerdo con sus gustos y preferencias.

Al proponer Rawls las libertades básicas, con ello está postulando y, al mismo tiempo, asegurando un valor equitativo a las libertades políticas, lo cual significa que cualquier persona, sea cual fuere, tiene el pleno derecho a acceder a cargos públicos o a influir de determinada manera en las decisiones políticas que de alguna forma lo inmiscuyen, ya que toda decisión política afecta a la sociedad y por ende al individuo que forma parte de ella, y es por lo que Rawls da una importancia relevante a las libertades políticas.

De esta manera, al postular dentro de las libertades básicas la libertad política y no alguna otra como la equidad económica, lo que intenta hacer o mostrar es que si existe un procedimiento político justo, lo demás viene de suyo, ya que será una decisión en la que de alguna manera habrán intervenido todos los individuos, esto es, realizar la democracia social a partir de garantizar las libertades. 